\title{
Profiling of Apoptosis-Related Genes in Erythrocytes of Chickens Infected with Avian Influenza Virus (H9N2 Subtype)
}

\author{
Muhammad Farhan Qadir', Xin-Yu Han', Meng-li Qiao1, Qian-qian Cheng', \\ Raza Ali Mangi ${ }^{1}$, Ali Raza Jahejo ${ }^{1}$, Afrasyab Khan ${ }^{1}$, Yu-hai Bi ${ }^{1,2}$ and Wen-xia Tian ${ }^{1 *}$ \\ ${ }^{1}$ College of Veterinary Medicine, Shanxi Agricultural University, Jinzhong 030801, \\ China
}

${ }^{2}$ CAS Key Laboratory of Pathogenic Microbiology and Immunology, Collaborative Innovation Center for Diagnosis and Treatment of Infectious Disease, Institute of Microbiology, Center for Influenza Research and Early-warning (CASCIRE), Chinese Academy of Sciences, Beijing 100101, China

\begin{abstract}
A B S T RA C T
Avian influenza virus (H9N2) is one of the major cause of illness in chickens with potential threats to human health. Chicken erythrocytes are known as most abundant circulating cells in the body which participate in inflammation and immune responses. Influenza viruses interact with the host cells at cell surface, leading to cell death in human and animals through apoptosis. Current study was designed to investigate the expression levels of apoptosis-related genes in the H9N2 infected chicken erythrocytes. qRT-PCR and Western blot techniques were performed to determine the expression levels of apoptosis-related genes including Bax, Bcl-2 BAG-1, BAG-3 and STAT3 in H9N2 infected erythrocytes of chickens for incubation time intervals of $0,2,6$ and $10 \mathrm{~h}$. The expression of all the genes related to apoptosis were significantly up-regulated at different time periods, except of Bcl-2 which was significantly down-regulated at 6 and $10 \mathrm{~h}$ of infection. To conclude, there are alterations in expression levels of apoptosis-related genes in chicken's erythrocytes at different time intervals that are highly related to the development of H9N2 infection. This study may provide a new biomarker to detect H9N2 infection in chickens.
\end{abstract}

\begin{tabular}{l} 
Article Information \\
\hline Received 03 August 2020 \\
Revised 13 October 2020 \\
Accepted 28 October 2020 \\
Available online 26 January 2021 \\
(early access) \\
Published 20 November 2021 \\
Authors' Contribution \\
\hline MFQ and WXT conceived and \\
designed the experiments. XYH, MLQ \\
and QQC analyzed the data. MFQ, \\
RAM, ARJ and AK performed the \\
experiments. YHB suggested analyses. \\
MFQ wrote the paper. MFQ and WXT \\
revised the manuscript. \\
Key words \\
\hline Avian influenza, Apoptosis, Chickens, \\
Erythrocytes, H9N2
\end{tabular}

Accepted 28 October 2020

(early access)

Published 20 November 202

Contribution

designed the experiments. XYH, MLQ

and QQC analyzed the data. MFQ,

(he

experiments. YHB suggested analyses.

MFQ wrote the paper. MFQ and WXT

Key words

Erythrocytes, H9N2

\section{INTRODUCTION}

A vian influenza (AI) is known as one of the economically important viral diseases of the chickens. It is an enveloped, negative, segmented single stranded RNA virus, belongs to the family Orthomyxoviridae. AI virus is classified into three types of influenza named as type A, B and C. Among these, type-A virus is of vital importance, effecting many avian species. On the basis of pathogenicity, AI virus can be categorized into two types named as low pathogenic avian influenza (LPAI) virus and highly pathogenic avian influenza (HPAI) virus (Fouchier et al., 2005; Palese and Shaw, 2007; Wang et al., 2015).

There are many subtypes of AI virus that are zoonotic, such as H9N2, H5N1 and H7N7. These three subtypes have been transmitted directly from birds to humans. Among all AI viruses, H9N2 avian influenza virus (AIV) is known as LPAIV that mainly affects poultry populations, human and pigs (Nagy et al., 2017; Xing et al., 2008).

\footnotetext{
Corresponding author: wenxiatian@126.com 0030-9923/2022/0001-0199 \$ 9.00/0 Copyright 2022 Zoological Society of Pakistan
}

LPAIV has been spread in domestic birds throughout Asia since the 1990s. It was reported that many species are affected by H9N2 virus including duck, chickens, quail, partridge, pheasant, chukar, pigeon that lead to huge economic losses (Huang et al., 2017). LPAIV was isolated in America in 1966, after that virus has been detected in many countries. H9N2 has been reported in poultry throughout Asia, Africa, the Middle East and Europe from 1995 to 1997. H9N2 AI virus was isolated from infected chickens in Guangdong province in 1994, known as first reported case of H9N2 in China. Most importantly, it was stated that $\mathrm{H} 9 \mathrm{~N} 2$ has the ability to cross the species boundaries to infect humans in Hong Kong and Guangzhou, China (Lv et al., 2015). LPAIV have also been known to donate internal genes to the highly pathogenic AIV (HPAIV) H5N1 in humans. In Hong Kong, H9N2 subtype was isolated from nasopharyngeal aspirates from three children detected with mild symptoms in the year 1999 and 2003 (Xing et al., 2011). H9N2 viruses have under-gone extensive reassortment with many subtypes of AI viruses, including HPAIV (H5N1 and H7N3) viruses. Moreover, H9N2 virus has a significant zoonotic threat, so poultry vaccination of entire poultry birds against H9N2 virus is a possible 
way to decrease infection and transmission among birds (Guan et al., 1999; Iqbal et al., 2013). Moreover, H9N2 virus can replicate in gut of birds and spreads by faecaloral transmission. H9N2 virus can spread with migration of birds, hence it is very difficult to prevent and control (Jahangir et al., 2010; Qu et al., 2012).

Chicken's erythrocytes are known as most abundant circulating cells in the body which are involved in inflammation and immune responses. Normally, chicken erythrocytes are large, nucleated, and sediment fast which makes them clear for titre determination. However, it is reported that human and chicken erythrocytes can be agglutinated by a variety of influenza a viruses, while avian and equine viruses can agglutinate horse and cow erythrocytes viruses (Ge and Wang, 2011). The viral hemagglutinin glycoprotein (HA) has been shown to mediate specific recognition and biding among the virus and target cell and from erythrocyte-influenza virus interaction. Chicken erythrocytes have been shown to actively form rosettes to facilitate the clearance of pathogens by macrophages, and could produce specific signalling molecules or cytokines in response to binding. It was hypothesized that a relationship between erythrocytes, haemoglobin and the immune system indicate an active role in the immune response to pathogen (Morera et al., 2011).

Apoptosis is known as programmed cell death in chickens and several genes are involved in regulating apoptosis. Apoptotic signals and permeabilization of the mitochondrial outer membrane are affected by the release of death promoting factors, which are regulated by the Bcl2 family of proteins. Bcl-2 and Bax both belong to Bcl-2 family of proteins and are considered as anti-apoptotic and pro-apoptotic members of this family respectively. In apoptosis pathway involving caspases showed that $\mathrm{p} 53$ and pro-apoptotic (Bax) activation occurs by some deathinducing stimuli, which further activates mitochondrial outer membrane permeabilization (MOMP) and apoptosome function leading to the cleavage of caspase- 9 and activation of caspase-3 (Wang et al., 2018). It was stated that BAG-1 is a multifunctional protein that has the ability to enhance the anti-apoptotic activity in association with Bcl-2. Similarly, BAG-3 has a similar function and apoptotic activities as BAG-1 in association with Bcl-2 family (Liao et al., 2001). Several studies reported that signal transducer and activator of transcription 3 (STAT3) takes part in apoptosis and cell growth regulation by promoting several genes expression in response to cellular stimuli. Hence, aberrant STAT3 signalling induces cell proliferation and inhibits apoptosis (Haberland et al., 2009; Fan et al., 2013; Wang et al., 2018).

Various studies have shown that apoptosis has been detected by different techniques such as flow cytometry, terminal deoxynucleotide transferase (TdT)-mediated nick and labelling (TUNEL) (Hatori et al., 1995; Xing et al., 2009) in chickens.

According to previous studies, apoptosis and prostaglandins (PG) related genes have been identified in the erythrocytes of chickens affected with Tibial dyschondroplasia (Tian et al., 2013). Influenza virus is responsible for cell death in different organisms by apoptosis and H9N2 can lead to lymphoid tissues damage by inducing apoptosis (Doustar et al., 2017). To date, there was no evidence of apoptosis-related genes expressed in H9N2 infected chicken's erythrocytes. Hence, we evaluated the mRNA levels of apoptosis-related genes and protein expression of Bax by qRT-PCR and Western blotting techniques in the chicken's erythrocytes infected with H9N2.

\section{MATERIALS AND METHODS}

\section{Experimental materials}

Specific pathogen-free (SPF) Esha brown chickens were purchased from Longkol Company (Taigu, Shanxi province, China). H9N2 a subtype of avian influenza A virus was obtained from Shenzhen Laboratory, (Takara, China). Dulbecco's Modified Eagle Medium (DMEM) was ordered from Beijing (Takara Bio Inc., China). H9N2 antibody serum was obtained from Longkol Company, (Taigu, Shanxi province, China). RNAiso Plus and Reverse transcription kits were obtained from Beijing, (Takara Bio Inc., China). Diethyl pyrocarbonate (DEPC) (Takara Bio Inc., Dalian, China) and phosphate buffer saline (PBS) were prepared manually.

\section{Erythrocyte isolation}

Pure erythrocytes were obtained by a procedure as described by Niu et al. (2018). $4 \mathrm{~mL}$ of fresh blood was taken from the wing vein of SPF chickens. Lymphocyte separation solution, PBS and blood were taken in 2:1:1 (8mL: 4mL: 4mL) ratio respectively. Initially, PBS was mixed to blood. Secondly, lymphocyte separation solution (superficial or upper layer) was added slowly to avoid the mixing, followed by centrifugation at $2000 \mathrm{r} / \mathrm{min}(268 \mathrm{~g}$ ) for 20 minutes. Supernatant was removed and infranatant (lying below a sediment) having pure erythrocytes was collected and separated. Then, it was re-suspended in PBS, centrifuged at $2000 \mathrm{r} / \mathrm{min}$ followed by 3 washings for 10 minutes each.

\section{Virus treatment}

$50 \mu 1$ of erythrocytes $\left(3 \times 10^{8}\right)$ were taken into 16 different centrifuge tubes containing DMEM maintenance 
solution. These 16 tubes were segregated into four main groups $(0,2,6$ and $10 \mathrm{~h})$ containing 4 each. In each group, four tubes were divided into control and experimental sub-groups. Then, H9N2 $100 \mu 1$ virus solution (the selected hemagglutination titer is $7 \log 2$ ) was added into experimental sub-groups of all 4 main groups followed by addition of $900 \mu \mathrm{l}$ of DMEM to make the final volume $1050 \mu \mathrm{l}$. While, the rest of sub-groups without H9N2 treatment were considered as control groups (Fig. 1). After completion of incubation with the virus, erythrocytes were isolated at $0,2,6$ and $10 \mathrm{~h}$ by centrifugation at $2000 \mathrm{r} / \mathrm{min}$ (revolution per minute) for 20 minutes. The supernatant was taken into Eppendorf tubes and stored separately. Erythrocytes were washed 3-times with PBS and stored at $-80^{\circ} \mathrm{C}$ for further experiments.
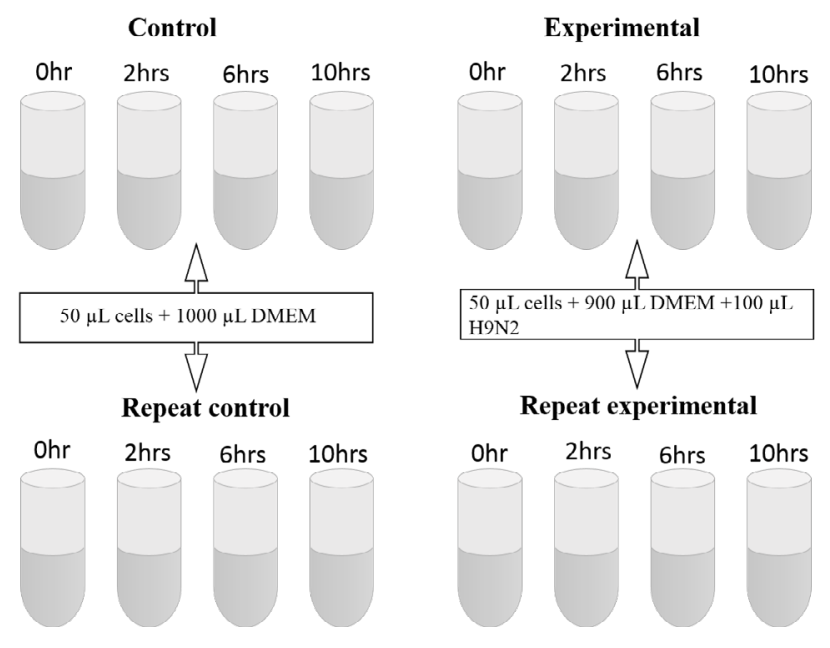

Fig. 1. Total volume used in control and experimental groups and their respective repeat groups at 0,2, 6 and 10 $\mathrm{h}$ of H9N2 infection.

\section{RNA extraction, $c D N A$ synthesis and $q R T-P C R$}

Total RNA was extracted and cDNA was synthesized by following the method explained by Wang et al. (2018). qRT-PCR was performed to determine the mRNA expression levels of apoptotic genes between control and experimental groups in erythrocytes of chicken. Primer express 3.0 was used to design the primers, and synthesized by Genery Biotechnology (Shanghai, China) and presented in Table I. 18SrRNA gene was taken as an internal control. These primers were selected for current study because virus stimulates erythrocytes to apoptosis as it was already reported in our previous study (Wang et al., 2018). TaKaRa SYBR Premix Ex Taq ${ }^{\text {TMII }}$ (Takara Bio Inc., Dalian, China) kit was used to perform Real-time PCR by 1:10 cDNA dilution, primers (1.5pmol) and final volume were set to the $10 \mu$ l. Thermal cycling conditions were maintained as $95^{\circ} \mathrm{C}$ (3minutes), 42 cycles of $95^{\circ} \mathrm{C}$ (30 seconds), $55^{\circ} \mathrm{C}$ (30 seconds), and final extension at $72^{\circ} \mathrm{C}$ for 10 seconds.

\section{Western blot analysis}

Western blotting was performed for Bax to validate the results of qRT-PCR. Cells were washed three times with PBS followed by incubation in $150 \mu 1$ lysis buffer on ice for half hour. Cell lysates were collected and centrifugation was done at $10,000 \mathrm{~g}$ for 8 minutes. Supernatant was taken for western blot analysis. Protein concentration was determined by BCA protein assay kit (Beyotime Institute of Biotechnology, Ltd.) by using Bovine albumin serum as standard. Then, the purified protein of $30 \mu \mathrm{l}$ was added in Eppendorf tube and $4 \times$ sample buffer solution $(10 \mu \mathrm{l})$ was mixed and placed at $100^{\circ} \mathrm{C}$ water bath for 5 mint heat to denature the protein. Denatured Protein was loaded and resolved by electrophoresis on $8 \%$ Sodium Dodecyl sulfate-polyacrylamide gel (SDS-PAGE) then, the required stripe was transferred on to a nitrocellulose (NC) membrane and run at $35 \mathrm{~V}$ for 60 minutes. 5\% dried milk (without fat) was used to block the blots for two $h$ followed by incubation with $\beta$-actin (dilution 1:1000, Santa Cruz Biotechnology, Inc., USA) and Bax (dilution 1:400, Santa Cruz Biotechnology, Inc., USA) primary antibodies overnight at $4{ }^{\circ} \mathrm{C}$. This anti-Bax antibody has no cross reactivity with the chicken proteins. Later, the membranes were incubated with HRP-conjugated goat anti-rabbit secondary antibody $(1: 3000)$ for $2 \mathrm{~h}$ at room temperature followed by PBST multiple washing, and protein bands were visualized by enhanced chemi-luminescence (Super ECL, KeyGEN BioTECH). Alpha View (version 3.2.2.0) software was used for optical density calculation. $\beta$-actin was set as an internal control.

\section{Statistical analysis}

The qRT-PCR data were analyzed by using the $2^{-\Delta \Delta C t}$. Experimental data were shown as mean \pm SEM. GraphPad Prism 5 software (GraphPad Software Inc., San Diego, USA) was used for statistical analyses. Two-way analysis of variance (ANOVA) followed by Tukey's multiple comparison test was used to compare the control and experimental groups. The value of $P<0.05$ was considered as statistically significant.

\section{RESULTS}

mRNA expression of apoptosis-related genes in chicken erythrocytes

mRNA expression levels of apoptosis-related genes including Bax, Bcl-2, BAG-1, BAG-3 and STAT3 were evaluated in control and experimental groups at incubation 
Table I. Apoptotic genes and primer sequences used for qRT-PCR.

\begin{tabular}{|c|c|c|c|}
\hline Genes & Primer's sequence $\left(5^{\prime} \rightarrow 3^{\prime}\right)$ & GenBank accession No. & Annealing temperature \\
\hline Bax & $\begin{array}{l}\text { Forward-GTGATGGCATGGGACATAGCTC } \\
\text { Reverse- TGGCGTAGACCTTGCGGATAA }\end{array}$ & XM422067 & $55^{\circ} \mathrm{C}$ \\
\hline Bcl-2 & $\begin{array}{l}\text { Forward- GGCAACAGTATGAGGCCTTT } \\
\text { Reverse- GATAAGCGCCAAGAGTGATG }\end{array}$ & NM_205339.2 & $55^{\circ} \mathrm{C}$ \\
\hline BAG-1 & $\begin{array}{l}\text { Forward- CCGTTTCTGTCACCGTCA } \\
\text { Reverse- CCTTTGCTAAAAATCCCTTC }\end{array}$ & NM_001109692.1 & $55^{\circ} \mathrm{C}$ \\
\hline BAG-3 & $\begin{array}{l}\text { Forward- TTCTGATTCTCCAACGGTTT } \\
\text { Reverse- TTCATGGATCACAGGAATTG }\end{array}$ & BI394174.1 & $55^{\circ} \mathrm{C}$ \\
\hline STAT3 & $\begin{array}{l}\text { Forward- TATGTCACCCCACCTCC } \\
\text { Reverse- CTGCTCCCTCGCTACTGT }\end{array}$ & NM_001030931.1 & $55^{\circ} \mathrm{C}$ \\
\hline 18SrRNA & $\begin{array}{l}\text { Forward- TTCCGATAACGAACGACAC } \\
\text { Reverse- GACATCTAAGGGCATCACAG }\end{array}$ & FM165414 & $55^{\circ} \mathrm{C}$ \\
\hline
\end{tabular}

Bax

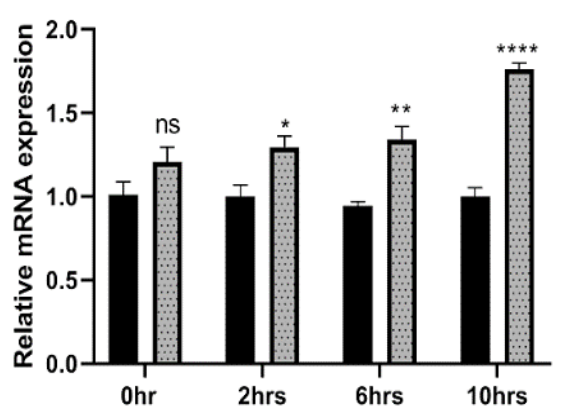

BAG-1

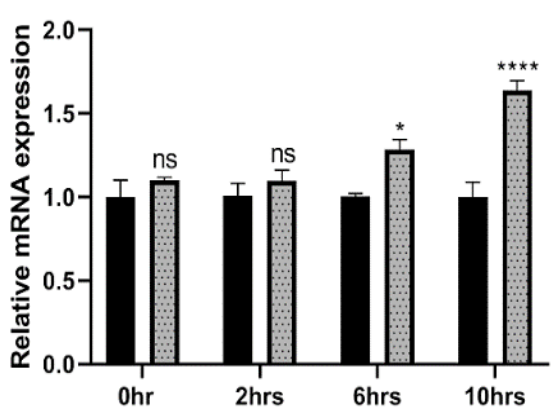

$\mathrm{Bcl}-2$

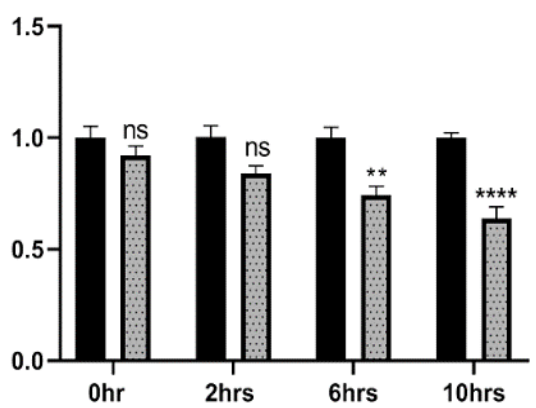

BAG-3

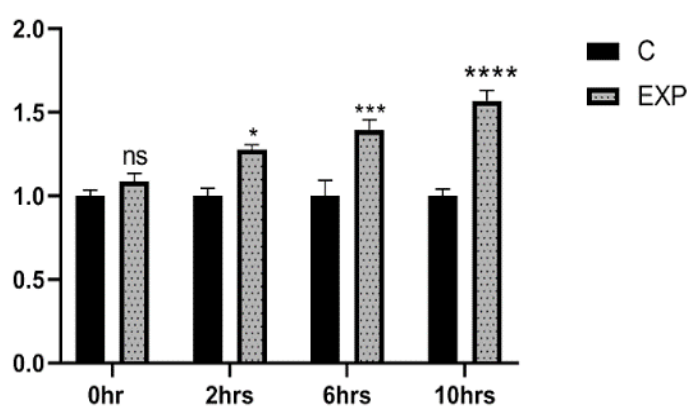

Fig. 2. mRNA expression of apoptosis-related genes in chicken's erythrocytes at different time intervals $(0,2,6$ and $10 \mathrm{~h})$. Asterisks $(*)$ indicating significant differences among experimental and control groups $(* P<0.05 ; * * P<0.01 ; * * * P<0.0004$; $* * * * P<0.0001 ;$ ns, not significant) C, control; EXP, experimental.

time intervals of $(0,2,6$ and $10 \mathrm{~h})$ (Fig. 2). mRNA expression levels of all apoptosis genes were up-regulated at all the time intervals except Bcl-2. Compared to their respective control groups, Bax and BAG-3 were significantly increased $(P<0.05)$ at 2,6 and $10 \mathrm{~h}$ while no significant changes were observed at 0 hour. STAT3 and BAG-1 were significantly up-regulated $(P<0.05)$ at 6 and
$10 \mathrm{~h}$, while no significant changes were observed at 0 and 2 $\mathrm{h}$ treatment. However, Bcl-2 expression level was different as compared to other genes, i.e. Bax, BAG-1, BAG-3 and STAT3. It was significantly decreased $(P<0.05)$ at 6 and $10 \mathrm{~h}$ while no significant results were observed at $0,2 \mathrm{~h}$ after infection in comparison with their respective control groups. Increase and decrease in expression levels 
suggested that apoptosis-related genes are involved in signal transduction triggered by AIV (H9N2 subtype).

\section{Expression changes of Bax at the protein level}

After evaluating the mRNA expression levels of apoptosis-related genes, we made an attempt to determine the protein expression of Bax by Western blotting (Fig. 3 ), and expression of Bax was increased and gradually increased as the time of incubation increased. Bax expression was up-regulated at 2, 6 and $10 \mathrm{~h}$ and significance was increased with the passage of infection. However, no significant changes were observed at 0 hour of infection, which was similar to mRNA expression results of Bax. So, protein expression of Bax supported the mRNA results of Bax. However, these results may create a hypothesis for rest of genes that, if Bax protein expression validate the mRNA expression of Bax, then protein expression level of all other apoptosis-related genes should also support the mRNA expression of their respective genes. Moreover, an increase in protein expression levels in response to H9N2 may involve in immune responses.

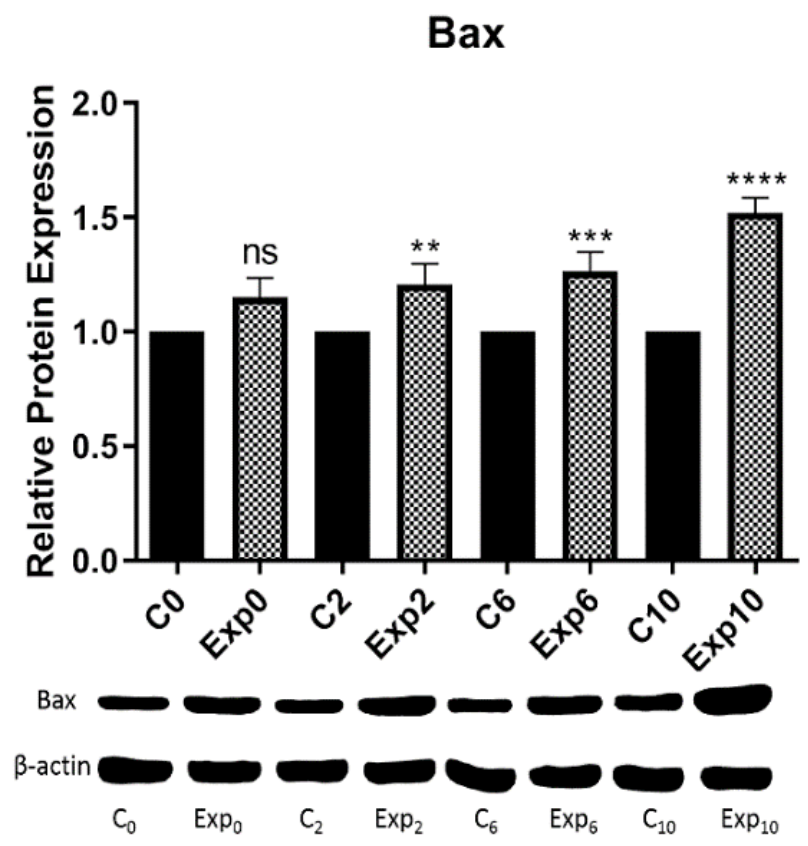

Fig. 3. Protein expression of Bax in chicken's erythrocytes at different time intervals of $0,2,6$ and $10 \mathrm{~h}$ (Protein bands derived from Western blot). Data represent mean \pm SEM. Asterisks $(*)$ indicating significant differences compared to control groups $(* P<0.05 ; * * P<0.01 ; * * * P<0.0004$; $* * * * P<0.0001$; ns, not significant) $\mathrm{C}$, control; EXP, experimental.

\section{DISCUSSION}

H9N2 AI viral infections can lead to mortality which varies from 5 to $30 \%$ and cause severe economic losses to the poultry industry and poultry farmers. Many researchers have already focused on evaluating the role of these viruses and the proteins that are involved in inducing apoptosis in various tissues of body (Ito et al., 2002). Bax was significantly up-regulated at 0,6 and $10 \mathrm{~h}$ while BAG-3 at 2,6 and $10 \mathrm{~h}$ of infection. Previous studies by Spampanato et al. (2012), Jiang et al. (2014), Wang et al. (2018) supported the current results, in which they investigated the expression levels of these genes which may initiate apoptosis in in cancer cells, T-cell lymphomas and chicken erythrocytes. These genes were significantly expressed due to reduced immunity level in birds, so the severity of H9N2 infection increases indicating that infection become more severe with an increase in incubation time. Apoptosis is the critical conserved genetic program of the immune system that ensures the infection severity with decrease in immune level of birds. Birds may prone to severe infection and inflammation, leading to cell death which may initiate the apoptosis in different parts of the body. Bax and Bcl-2 genes act as antagonistic because Bax is known as proapoptotic gene and Bcl-2 is called an anti-apoptotic gene. Bcl-2 is also helpful in cell survival and differentiation. So, according to mechanism of pro and anti-apoptotic genes, an increased level of Bax with concomitant decrease in Bcl-2 may initiate the apoptosis. However, present results of Bcl-2 which were significantly down-regulated at 6 and $10 \mathrm{~h}$ of infection. Previous studies by Spampanato et al. (2012) and Huang et al. (2013) supported the current Bcl-2 findings, they investigated the expression of Bcl-2 which may initiate the apoptosis. It has also been reported that pro-apoptotic proteins activation results in the induction of cytochrome $\mathrm{c}$, which is released from mitochondria to the cytoplasm. Moreover, Bcl-2 proteins can block the cytochrome c release and prevent cell death, induced by Bax (Saito et al., 2000; Wei et al., 2001; Jiang and Wang, 2004). In this study, increased expression of Bax with simultaneous decrease levels of Bcl-2 expression may lead to the release of cytochrome $\mathrm{c}$, which may initiate apoptosis process.

STAT3 and BAG-1 were significantly increased at 6 and $10 \mathrm{~h}$, however no significant changes were observed at 0 and $2 \mathrm{~h}$ revealing that infection severity was increased with the passage of time which may be due to decreased immunity level of birds so, infection was more severe in later hour of incubation period. Most of the recent studies reported increased expression of BAG-1 and STAT3 in human epidermal squamous cell carcinoma, B-cell lymphoma, chicken erythrocytes and renal cell carcinoma, 
which supports the findings of current study (Wood et al., 2011; Ok et al., 2014; Wang et al., 2018; Robinson et al., 2019). Hence, expression levels of these genes at all stages may be considered as a response of host to virus indicating that, this gene is involved in H9N2 infection in the erythrocytes of chickens at different stages of time period.

Bcl-2 relative mRNA expression levels were different as compared to other apoptotic genes. It was significantly down-regulated at 6 and $10 \mathrm{~h}$ after infection, while not significant at 0 and $2 \mathrm{~h}$ of infection as compared with their respective control groups, showing that severity of H9N2 decreased with the passage of time. Previous study supported our current Bcl-2 findings in which, they reported that the increased Bax expression and decreased Bcl-2 initiates the apoptosis finally leading to oxidative stress in the broiler chickens (Huang et al., 2013).

Generally, H9N2 promoted the expression of apoptotic genes with the passage of time, which indicate that these genes probably have vital role in H9N2 induced infection. Up-regulated expression of these apoptosisrelated genes indicate the severity of H9N2 infection at different time periods, and it can be seen that severity of infection increases as the infection time persists except for Bcl-2. Actually, a decrease in Bcl-2 and an increase in other apoptotic genes may involve in programmed cell death.

Further, western blotting was done to determine the protein expression levels of Bax. At 0,2, 6 and $10 \mathrm{~h}$ of a time interval, in comparison with their respective control groups, protein expression of Bax was significantly up-regulated, and this significance increased with the persistence of infection or passage of time. However, no significant changes were observed at 0 hour of infection. So, birds were more prone to infection with the passage of time due to decreased immune level of birds. Hence, severity of infection increased in later $\mathrm{h}$ of incubation period. Spampanato et al. (2012) also observed the similar protein expression of Bax in their study indicating the apoptosis in cancer cell lines and they stated that high level of increase in Bax and low level of Bcl-2 plays a vital role in determining the programmed cell death. All the results revealed that erythrocytes have the tendency to respond the viral infections such as H9N2.

In conclusion, apoptosis-related genes in erythrocytes of chickens are closely related to development of H9N2 infection. Current findings have provided a new perspective by targeting apoptosis-related genes in H9N2 infected chicken's erythrocytes. Protein expression results of Bax supported the mRNA expression level of Bax. Moreover, these apoptosis genes may provide a new biomarker to detect H9N2 infection in chickens. However, further studies are necessary to know morphological features and, to check the mechanism of erythrocytes response against H9N2.

\section{ACKNOWLEDGMENT}

This work was supported by the National Key R and D Program (2016YFD0500800, 2016YFD0500806), the China-U.S. Collaborative Program on Emerging and Re-emerging Infectious Diseases, "131" Leading Talent Project for Colleges and Universities of Shanxi Province, Scientific and Technological Innovation Team for Disease Control and Prevention in Shanxi Agricultural University.

Statement of conflict of interest

The authors have declared no conflict of interest.

\section{REFERENCES}

Doustar, Y., Troughi, R., Hashemi, M., Mohajeri, D. and Movafagh, A., 2017. An experimental study on apoptosis in lymphoid tissues of SPF chicken after avian influenza serotypes H9N2 infection. Asian Pac. J. Cancer Biol., 2: 81-84. https://doi. org/10.31557/apjcb.2017.2.4.81-84

Fan, Y., Mao, R. and Yang, J., 2013. NF-кB and STAT3 signaling pathways collaboratively link inflammation to cancer. Protein Cell., 4: 176-185. https://doi.org/10.1007/s13238-013-2084-3

Fouchier, R.A., Munster, V., Wallensten, A., Bestebroer, T.M., Herfst, S., Smith, D., Rimmelzwaan, G.F., Olsen, B. and Osterhaus, A.D., 2005. Characterization of a novel influenza A virus hemagglutinin subtype (H16) obtained from blackheaded gulls. J. Virol., 79: 2814-2822. https://doi. org/10.1128/JVI.79.5.2814-2822.2005

Ge, S. and Wang, Z., 2011. An overview of influenza a virus receptors. Crit. Rev. Microbiol., 37: 157-165. https://doi.org/10.3109/1040841X.2010.536523

Guan, Y., Shortridge, K.F., Krauss, S. and Webster, R.G., 1999. Molecular characterization of H9N2 influenza viruses: Were they the donors of the "internal" genes of H5N1 viruses in Hong Kong? Proc. natl. Acad. Sci., 96: 9363-9367. https://doi. org/10.1073/pnas.96.16.9363

Haberland, M., Montgomery, R.L. and Olson, E.N., 2009. The many roles of histone deacetylases in development and physiology: implications for disease and therapy. Nat. Rev. Genet., 10: 32-42. https://doi.org/10.1038/nrg2485

Hatori, M., Klatte, K.J., Teixeira, C.C. and Shapiro, I.M., 1995. End labeling studies of fragmented 
DNA in the avian growth plate: evidence of apoptosis in terminally differentiated chondrocyte. J. Bone Miner. Res., 10: 1960-1968. https://doi. org/10.1002/jbmr.5650101216

Huang, J., Cui, H., Peng, X., Fang, J., Zuo, Z., Deng, $\mathrm{J}$. and $\mathrm{Wu}, \mathrm{B} ., 2013$. The association between splenocyte apoptosis and alterations of Bax, Bcl2 and caspase- 3 mRNA expression, and oxidative stress induced by dietary nickel chloride in broilers. Int. J. Env. Res. Publ. Hlth., 10: 7310-7326. https:// doi.org/10.3390/ijerph10127310

Huang, L., Hou, Q., Ye, L., Yang, Q. and Yu, Q., 2017. Crosstalk between H9N2 avian influenza virus and crypt-derived intestinal organoids. Vet. Res., 48: 71. https://doi.org/10.1186/s13567-017-0478-6

Iqbal, M., Yaqub, T., Mukhtar, N., Shabbir, M.Z. and McCauley, J.W., 2013. Infectivity and transmissibility of H9N2 avian influenza virus in chickens and wild terrestrial birds. Vet. Res., 44: 100. https://doi.org/10.1186/1297-9716-44-100

Ito, T., Kobayashi, Y., Morita, T., Horimoto, T. and Kawaoka, Y., 2002. Virulent influenza A viruses induce apoptosis in chickens. Virus Res., 84: 27-35. https://doi.org/10.1016/S0168-1702(01)00414-2

Jahangir, A., Ruenphet, S., Hara, K., Shoham, D., Sultana, N., Okamura, M. and Takehara, K., 2010. Evaluation of human intestinal epithelial differentiated cells (Caco-2) for replication, plaque formation and isolation of avian influenza viruses. J. Virol. Methods, 169: 232-238. https://doi. org/10.1016/j.jviromet.2010.07.023

Jiang, L., Zhao, Z., Menke, D. and Rizzo, K., 2014. Correlation of BAG-3 and heat shock protein 70 with CD30 expression in T-cell lymphomas. Sci. Rep., 4: 1-5. https://doi.org/10.1038/srep03952

Jiang, X. and Wang, X., 2004. Cytochrome C-mediated apoptosis. Annu. Rev. Biochem., pp. 7.

Liao, Q., Ozawa, F., Friess, H., Zimmermann, A., Takayama, S., Reed, J.C., Kleeff, J. and Büchler, M.W., 2001. The anti-apoptotic protein BAG-3 is overexpressed in pancreatic cancer and induced by heat stress in pancreatic cancer cell lines. FEBS Lett., 503: 151-157. https://doi.org/10.1016/S00145793(01)02728-4

Lv, J., Wei, L., Yang, Y., Wang, B., Liang, W., Gao, Y., Xia, X., Gao, L., Cai, Y. and Hou, P., 2015. Amino acid substitutions in the neuraminidase protein of an H9N2 avian influenza virus affect its airborne transmission in chickens. Vet. Res., 46: 44. https:// doi.org/10.1186/s13567-014-0142-3

Morera, D. and MacKenzie, S.A., 2011. Is there a direct role for erythrocytes in the immune response? Vet.
Res., 42: 1-8. https://doi.org/10.1186/1297-971642-89

Nagy, A., Mettenleiter, T. and Abdelwhab, E., 2017. A brief summary of the epidemiology and genetic relatedness of avian influenza H9N2 virus in birds and mammals in the Middle East and North Africa. Epidemiol. Infect., 145: 3320-3333. https://doi. org/10.1017/S0950268817002576

Niu, S., Jahejo, A.R., Jia, F.J., Li, X., Ning, G.B., Zhang, D., Ma, H.I., Hao, W.f., Gao, W.W. and Zhao, Y.J., 2018. Transcripts of antibacterial peptides in chicken erythrocytes infected with Marek's disease virus. BMC Vet. Res., 14: 363. https://doi. org/10.1186/s12917-018-1678-7

Ok, C.Y., Chen, J., Xu-Monette, Z.Y., Tzankov, A., Manyam, G.C., Li, L., Visco, C., Montes-Moreno, S., Dybkær, K. and Chiu, A., 2014. Clinical implications of phosphorylated STAT3 expression in de novo diffuse large B-cell lymphoma. Clin. Cancer Res., 20: 5113-5123. https://doi. org/10.1158/1078-0432.CCR-14-0683

Palese, P. and Shaw, M.L., 2007. Orthomyxo-viridae: The viruses and their replication. In: Fields virology (eds. D.M. Knipe and P.M. Howley). Lippincott Williams and Wilkins, Philadelphia. pp. 1647-1689.

Qu, B., Li, X., Gao, W., Sun, W., Jin, Y., Cardona, C.J. and Xing, Z., 2012. Human intestinal epithelial cells are susceptible to influenza virus subtype H9N2. Virus Res., 163: 151-159. https://doi.org/10.1016/j. virusres.2011.09.007

Robinson, R.L., Sharma, A., Bai, S., Heneidi, S., Lee, T.J., Kodeboyina, S.K., Patel, N. and Sharma, S., 2019. Comparative STAT3-regulated gene expression profile in renal cell carcinoma subtypes. Front Oncol., 9: 72. https://doi.org/10.3389/ fonc. 2019.00072

Saito, M., Korsmeyer, S.J. and Schlesinger, P.H., 2000. BAX-dependent transport of cytochrome c reconstituted in pure liposomes. Nat. Cell Biol., 2: 553-555. https://doi.org/10.1038/35019596

Spampanato, C., De Maria, S., Sarnataro, M., Giordano, E., Zanfardino, M., Baiano, S., Cartenì, M., Morelli, F., 2012. Simvastatin inhibits cancer cell growth by inducing apoptosis correlated to activation of Bax and down-regulation of BCL-2 gene expression. Int. J. Oncol., 40: 935-941. https://doi.org/10.3892/ ijo.2011.1273

Tian, W.X., Li, J.K., Qin, P., Wang, R., Ning, G.B., Qiao, J.G., Li, H.Q., Bi, D.R., Pan, S.Y., Guo, D.Z., 2013. Screening of differentially expressed genes in the growth plate of broiler chickens with tibial 
dyschondroplasia by microarray analysis. $B M C$ Genomics, 14: 276. https://doi.org/10.1186/14712164-14-276

Wang, C., Niu, S., Jahejo, A., Jia, F., Li, Z., Zhang, N., Ning, G., Zhang, D. and Ma, H., 2018. Identification of apoptosis-related genes in erythrocytes of broiler chickens and their response to thiram-induced tibial dyschondroplasia and recombinant glutathione-Stransferase A3 protein. Res. Vet. Sci., 120: 11-16. https://doi.org/10.1016/j.rvsc.2018.08.001

Wang, J., Tang, C., Wang, Q., Li, R., Chen, Z., Han, X., Wang, J. and Xu, X., 2015. Apoptosis induction and release of inflammatory cytokines in the oviduct of egg-laying hens experimentally infected with H9N2 avian influenza virus. Vet. Microbiol., 177: 302314. https://doi.org/10.1016/j.vetmic.2015.04.005

Wei, M.C., Zong, W.-X., Cheng, E.H.-Y., Lindsten, T., Panoutsakopoulou, V., Ross, A.J., Roth, K.A., MacGregor, G.R., Thompson, C.B. and Korsmeyer, S.J., 2001. Proapoptotic BAX and BAK: A requisite gateway to mitochondrial dysfunction and death. Science, 292: 727-730. https://doi.org/10.1126/ science. 1059108

Wood, J., Pring, M., Eveson, J., Price, N., Proby, C. and Hague, A., 2011. Co-overexpression of Bag1 and heat shock protein 70 in human epidermal squamous cell carcinoma: Bag-1-mediated resistance to 5-fluorouracil-induced apoptosis. $\mathrm{Br}$. J. Cancer, 104: 1459-1471. https://doi.org/10.1038/ bjc. 2011.111

Xing, Z., Cardona, C.J., Adams, S., Yang, Z., Li, J., Perez, D. and Woolcock, P.R., 2009. Differential regulation of antiviral and proinflammatory cytokines and suppression of Fas-mediated apoptosis by NS1 of H9N2 avian influenza virus in chicken macrophages. J. Gen. Virol., 90: 11091118. https://doi.org/10.1099/vir.0.007518-0

Xing, Z., Cardona, C.J., Li, J., Dao, N., Tran, T. and Andrada, J., 2008. Modulation of the immune responses in chickens by low-pathogenicity avian influenza virus H9N2. J. Gen. Virol., 89: 12881299. https://doi.org/10.1099/vir.0.83362-0

Xing, Z., Harper, R., Anunciacion, J., Yang, Z., Gao, W., Qu, B., Guan, Y. and Cardona, C.J., 2011. Host immune and apoptotic responses to avian influenza virus H9N2 in human tracheobronchial epithelial cells. Am. J. Resp. Cell. Mol. Biol., 44: 24-33. https://doi.org/10.1165/rcmb.2009-0120OC 